\title{
TIME LAGS OF ONLINE ADVERTISING: USING INTERACTIVE AD CHANNELS TO ATTRACT EXISTING AND NEW CUSTOMERS
}

\author{
Ralph Breuer, RWTH Aachen University, Germany \\ Malte Brettel, RWTH Aachen University, Germany
}

\begin{abstract}
Although online advertising has become a full element of the marketing mix and is still growing in importance, studies of long-term, or lagged, advertising effects have generally either neglected interactive online advertising channels or have treated online advertising as one uniform block. We analyze the short- and long-term effectiveness of different types of interactive online advertising channels with special attention to the differences between existing and new customers.

We look at the sales effect of search engine marketing (SEM), banner advertising, price comparison advertising (PCA) and customer loyalty program advertising (CLA) using a sample of 2.8 million purchases and over 1.1 million individual costumers. The data spans a period of 365 days and was obtained from the .com-website of a leading online-platform for used and antiquarian books.
\end{abstract}

Since SEM, banner advertising, and CLA are widely know we will focus our brief introduction on PCA:

Price comparison websites are internet service platforms that allow users to compare prices across a wide variety of retailers. Next to each displayed price there is a link to the retailers' website, and clicks on these links can be counted to determine effectiveness. Since retailers pay to be listed on these price comparison websites and can improve their ranking position by paying a premium, price comparison websites are much more an advertising channel than an objective tool to screen the market. Therefore, we call placement on such sites price comparison advertising (PCA). Like search engine advertising PCA is a type of interactive on-demand advertising (Rappaport 2007).

The model used to estimate carryover effects of advertising is based on the direct aggregation approach derived from Srinivasan and Weir (1988) and works as described in Herrington and Dempsey (2005). It delivers a separate $\lambda$-values for the carryover effect of each advertising channel and is estimated with Stata 11 using Generalized Least Squares.

The findings indicate that different online advertising channels have different carryover effects (e.g. $\lambda_{\mathrm{PCA}, \mathrm{EC}}: 0.05$ vs. $\lambda_{\mathrm{SEM}, \mathrm{NC}}$ : 0.65 ), which means that their sales impact ranges between less than a day (e.g. PCA $\mathrm{ACC}_{\mathrm{EC}} 0.8$ days) and a couple of days (e.g. $\mathrm{SEM}_{\mathrm{NC}}: 5.3$ days). Only by using the direct aggregation approach with separate $\lambda$-values for each advertising channel that we employed here, instead of a one-size-fits-all $\lambda$ for all channels together, it is possible to identify the appropriate carryover effect for each advertising channel.

Our calculations show that in the analyzed sample, all else being equal, banners and CLA are working better to target existing customers whereas PCA is better suited to attract new customers. Although those results might vary by e.g., product category or ad content, our contribution is the approach of how to consider time-lags and long-term advertising effects when analyzing the target group specific effectiveness of different online advertising channels. On top of this general marketing research can profit from our results because the approach can also be used for offline and mixed offline/online environments to improve marketing mix decision.

The results indicate that existing studies that ignore long-term effects of advertising, use a one-size-fits-all $\lambda$ for all channels, or do not differentiate between target groups could be improved by considering those elements which significantly influence advertising success.

Several avenues for further research exist. To keep it short we present only one of the avenues: It would be interesting to understand the influence of physical differences between online and offline advertising on its effectiveness. In particular we ask: Do physical circumstances of online, in comparison to offline advertising (e.g. customer has to leave its house after watching a TV ad, before he/she can buy the advertised product) influence psychological effects of advertising (e.g. intermediate ad effects)?

References available upon request 